This item was submitted to Loughborough's Research Repository by the author.

Items in Figshare are protected by copyright, with all rights reserved, unless otherwise indicated.

\title{
Ageing (dis)gracefully: Enabling designers to understand material change
}

PLEASE CITE THE PUBLISHED VERSION

https://doi.org/10.1016/j.jclepro.2019.01.304

PUBLISHER

(c) Elsevier

VERSION

AM (Accepted Manuscript)

PUBLISHER STATEMENT

This paper was accepted for publication in the journal Journal of Cleaner Production and the definitive published version is available at https://doi.org/10.1016/j.jclepro.2019.01.304

\section{LICENCE}

CC BY-NC-ND 4.0

\section{REPOSITORY RECORD}

Lilley, Debra, Ben Bridgens, Adam Davies, and A. Holstov. 2019. "Ageing (dis)gracefully: Enabling Designers to Understand Material Change". figshare. https://hdl.handle.net/2134/36769. 


\title{
Ageing (dis)gracefully: \\ enabling designers to understand material change
}

\author{
Lilley D. ${ }^{(a)}$ Bridgens B. ${ }^{(b)^{*}}$ Davies. $A^{(a)}$ Holstov. $A^{(c)}$
}

a) Loughborough University, Design School, Loughborough, UK

b) Newcastle University, School of Architecture, Planning and Landscape, Newcastle-upon-Tyne, UK

c) Newcastle University, School of Engineering, Newcastle-upon-Tyne, UK

* Corresponding author: Ben Bridgens, ben.bridgens@ncl.ac.uk, School of Architecture, Planning and Landscape, The Quadrangle, Newcastle University, Newcastle-upon-Tyne, NE1 7RU, UK

Keywords: material change; cosmetic obsolescence; patina; graceful ageing; materials library.

\begin{abstract}
From the moment of purchase, pristine objects are subjected to an array of stimuli including wear, impact, heat, light, water and air which alter their tactile and aesthetic properties. Material change is often regarded as 'damage' or 'degradation' and contributes to premature obsolescence but has potential to be used as a tool to engender emotional engagement with an object and extend product lifetimes. However, materials resources for designers rarely provide information about how materials will change in use. In this paper we draw on a combination of literature and user studies to elucidate the complex web of factors which contribute to changes in material surfaces, which we present in a 'framework for understanding material change'. We go on to explore the role that changes to product material surfaces, and the design of objects to change in particular ways with use, could have on the transition to circular modes of consumption. A range of resources which aim to increase designers' understanding of material change are presented, and the challenges of creating, utilising and developing these resources are discussed.
\end{abstract}




\section{Introduction}

The process of material selection is usually focused on the pristine, mass-produced object that entices the purchaser, but from the moment of purchase the surface of an object changes in response to use and interaction with its environment (Figure 1): “...the formal language of design has notably shifted to a space dominated by the smooth and opaque surface. Such impenetrable surfaces make it easy to forget that the materials from which it was made are kinetic, that it is their 'will' to decay or change state" (Carr and Gibson, 2015). Abrasion, polishing, ablation, impact, accumulated dirt, mould and oxidation combine to create a surface 'patina' that discloses the life of the object (Candy et al., 2004; Giaccardi et al., 2014). Patina can create an emotional bond between the owner and object, either through memories of particular events or because the change to the surface is aesthetically pleasing (referred to as 'graceful ageing'). However, these processes are often not considered during the design process: "Industrial design usually produces objects to be used in the future, but rarely investigates how these objects will change in time" (Nobels et al., 2015).
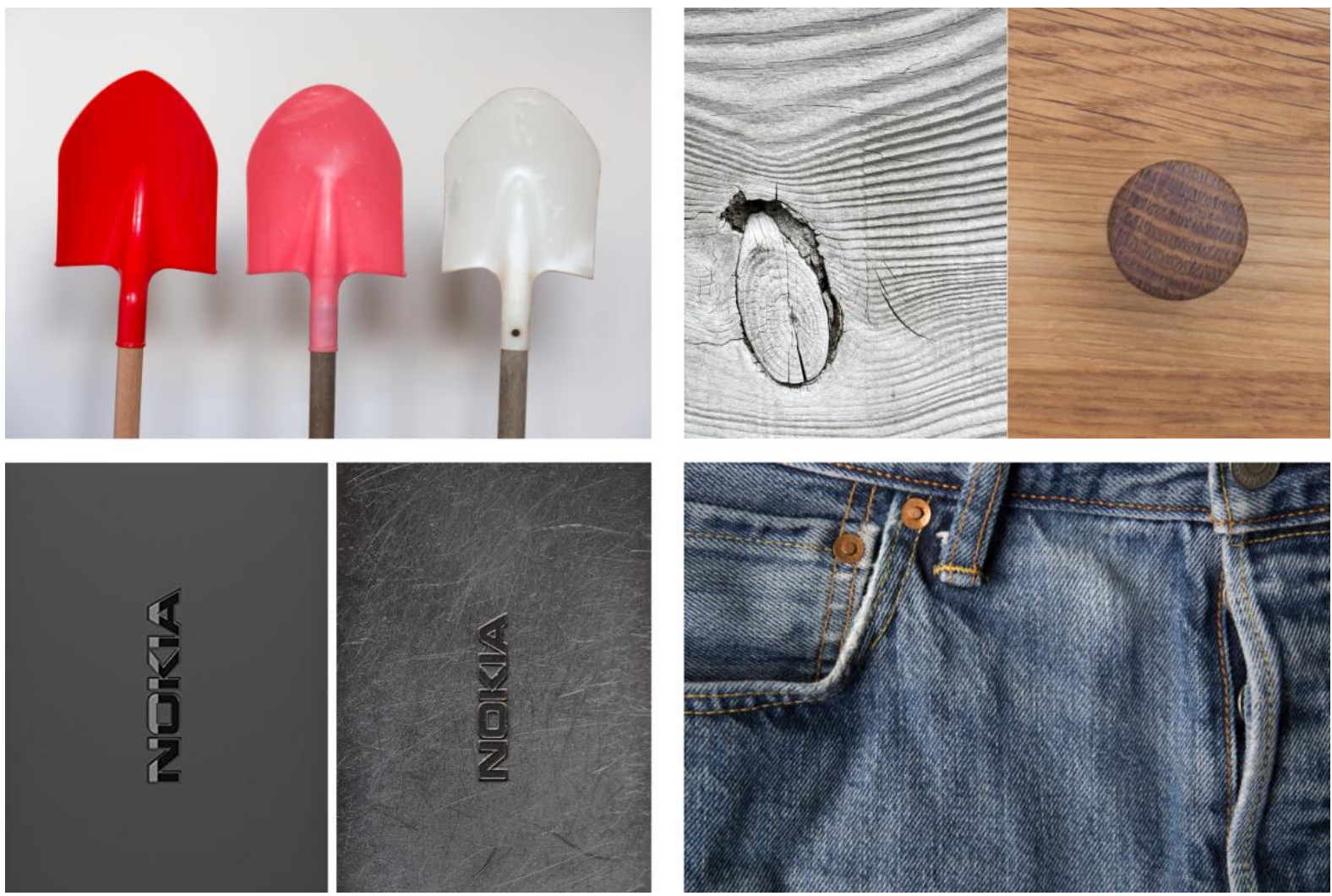

Figure 1. Materials change (clockwise from top left): a plastic spade is severely faded by sunlight despite being designed for outdoor use, shown new and after one and two year's use in Northern England; timber cladding exposed to sunlight, water and wind changes colour to a silvery grey (this is a colour photograph) and the texture of the grain is emphasised as the weaker 'early wood' in each growth ring is broken down; oiled oak furniture, the wood has darkened and the grain patterns have been emphasised after 10 years of exposure to air and indirect sunlight, the circular knob is the same material but has darkened considerably due to oils and polishing from being touched regularly; denim fades from dark blue to white with repeated washing and use, this appearance is highly valued and many products are 'pre-aged' by the manufacturer by stone washing; an ABS plastic mobile phone gradually accumulates scratches which can clearly be seen on the smooth, shiny surface (left: manufacturer's image left, right: after three year's use).

Material change is commonly perceived as damage or degradation, and for many types of product 'cosmetic obsolescence' contributes to premature disposal and unsustainably short product lifetimes 
(Packard, 1963; Cooper, 2005; Manley, Lilley and Hurn, 2015b; Lilley et al., 2016). Potential purchasers are enticed by 'newness', which is a complex combination of sensorial properties which often includes uniformity of surfaces and shininess (Nobels et al., 2015). Delight at the untouched appearance of new products which "invites sensual engagement" (Maffei and Fisher, 2013) can rapidly change to dissatisfaction with 'worn' or 'aged' materials which, coupled with persuasive advertising, drives the cycle of replacement of products which are often fully functional when disposed of (Woolley, 2003; Hollander, Bakker and Hultink, 2017).

In response to the negative impacts of the linear 'take-make-use-waste' economy, and its increasing fragility in the light of material scarcity and price volatility, there is a growing emphasis on 'slowing' and 'closing' resource loops through a transition to the 'circular economy' (CE) (European Commission, 2015; British Standards Institution, 2017; Prieto-Sandoval, Jaca and Ormazabal, 2017). Whilst many CE strategies involve industrial reuse, remanufacture or recycling with associated impacts due to transportation and processing, another approach is to slow resource loops with approaches including 'design for longevity' (Park, 2009) and 'design for product attachment' (Bakker et al., 2014). Whilst 'graceful ageing' of material surfaces is a potential strategy for creating enduring products, emotional attachment is difficult to predict and often elusive (Ball and Tasaki, 1992; Cooper, 2005; Connor-Crabb, Miller and Chapman, 2016). "Objects capable of sustaining long-lasting relationships with consumers are rare" (Chapman, 2005) due to unreasonably high expectations and rapid loss of novelty.

Carefully orchestrated material change has the potential to be leveraged to increase product lifetimes through creating and sustaining both physical and emotional durability. Designing for emotional durability is a well-established but little-used design concept, proposed by Chapman (Chapman, 2005) but notoriously difficult to implement. To address this, this manuscript brings together ideas and findings from different disciplines to propose a starting point for designers to better understand material change. We discuss the limitations of existing materials specification resources, propose a framework for better understanding the role of material change in product design, and describe the development of a resource which aims to help designers understand how materials will change and incorporate this understanding in their design process.

\section{Background}

\subsection{Designing for appropriate product lifetimes in the context of the circular economy}

The circular economy is normally described in terms of circular flows of materials, being: "a simple, but convincing, strategy, which aims at reducing both input of virgin materials and output of wastes..." (Haas et al., 2015), and can equally be seen as a way of maintaining the value of products, components and materials as products move between users and uses (Baxter, Aurisicchio and Childs, 2017). This 'simple strategy' actually comprises an array of different approaches which are fundamentally different in terms of design requirements and implementation. These include extending the use phase of products ('product longevity'), reuse, repair and remanufacture of components or complete products, and recycling of materials. Large-scale implementation of these strategies is usually by 'top-down' adoption of new 'Product Service System (PSS)' business models which shift the emphasis from product sales to service provision, enabling businesses to maintain ownership of their products and components and therefore incentivise them to design for longevity and repair.

Consumer behaviour can significantly influence the flow of products, components and materials within the circular economy. A such, there is a small but increasing awareness of the importance of involving citizens in the circular economy, in terms of consumer acceptance of, and engagement with, new 'models of consumption' (Hobson, 2015; Edbring, Lehner and Mont, 2016; Lofthouse and Prendeville, 2018; Wastling, Charnley and Moreno, 2018) and wider questions about the social and cultural 
consequences of the proposed circular production and consumption systems (Hobson and Lynch, 2016; Korhonen et al., 2018). An alternative strategy to top-down product service systems is consumer led product longevity (through care, maintenance and repair) and community facilitation of reuse and sharing. These approaches have environmental benefits in terms of minimising transport and reprocessing impacts, and social benefits through creating communities of sharing and repair.

We consider the role that changes to product material surfaces, and the design of objects to change in particular ways with use, could have on the transition to circular modes of consumption. In the context of material and product reuse through the circular- or sharing- economy, is it beneficial to engender emotional attachment to an object through material change? The answer is, of course, complex and answering it requires speculative life-cycle analysis of multiple possible product life scenarios, which will be different for every product and the tools are not available for designers to carry out this type of analysis quickly and effectively (Lee et al., 2015; Bridgens et al., 2017). Most forms of re-use, remanufacturing and recycling will entail negative environmental impacts due to transportation and processing. Product longevity avoids these impacts and therefore has the potential to minimise environmental impacts. However, for products which require energy in the use phase (e.g. electronic devices, cars and buildings) (Van Nes and Cramer, 2006; Suckling and Lee, 2015) or substantial maintenance (Kara et al., 2008), it may actually be beneficial to replace (or upgrade) older inefficient products with newer models, or to 'optimise' lifetimes to an appropriate length rather than 'extend' indefinitely (Charter and Tischner, 2017). Judicious use of emotional attachment for product lifespan extension is also advised: "It is repellent, to conceive of a material world, in which all possessions are priceless and indispensable" (Chapman, 2015). However, for many products even a modest increase in longevity provides a simple and effective strategy to reduce environmental impact (Cooper, 2016).

In addition to product longevity, many approaches to the circular economy involve implementation of new 'Product Service Systems' which transition from private ownership of products to provision of services, leasing, or shared ownership (Bardhi and Eckhardt, 2012; Rogers et al., 2015). A key consideration is that whilst material change may be viewed positively for a product that is owned by an individual, traces of use on the material surface are more likely to be perceived as 'contamination' when the object is shared, changes owner or is in public ownership (e.g. public spaces and public transport vehicles) (Edbring, Lehner and Mont, 2016). There are two distinct forms of contamination: technical contamination in which the purity of the materials is compromised making them more difficult to recycle (as opposed to downcycle) (McDonough and Braungart, 2002), and interaction contamination in which material change leaves traces of use on an object (Baxter, Aurisicchio and Childs, 2017). This highlights the importance of understanding the nature of material change in relation to the intended path(s) that the object will take through the circular economy.

\subsection{Existing materials resources for designers and their limitations}

A range of material selection resources are used both to educate design students, and to inform material selection in design practice (van Kesteren, 2008; Akin and Pedgley, 2016; Asbjørn-Sörensen, Jagtap and Warell, 2016). These resources for material selection typically consider mechanical or engineering properties (such as strength and stiffness), manufacturing processes and environmental impacts but rarely provide information about either people's senso-aesthetic responses to materials or how materials change in use (Akin and Pedgley, 2016); "Physical parameters... are typically used to predict how a material will perform in technical applications, but the ways in which materials are perceived by the people that use them are less well studied by the materials science community" (Wilkes et al., 2016). Akin and Pedgley's (2016) review of materials library provision, for example, makes no reference to material change or durability.

Online resources provide detailed technical engineering properties including some measure of functional durability, such as numerical durability ratings for different types of environmental exposure (e.g. exposure to acids and alkalis and ultraviolet light). Typically these resources are written in "the 
language of materials science [which] is not often taught to designers" (Wilkes et al., 2016), however Granta Design ${ }^{1}$ are trying to bridge this divide by including sensorial properties and simplified material data in their prototype Products, Materials \& Processes database (Ashby and Johnson, 2013) (Figure 2 ), which aims to engage both engineers and designers with material selection, through productcentred, visually inspiring case studies. However, this resource currently provides no information about aesthetic and tactile changes with use.

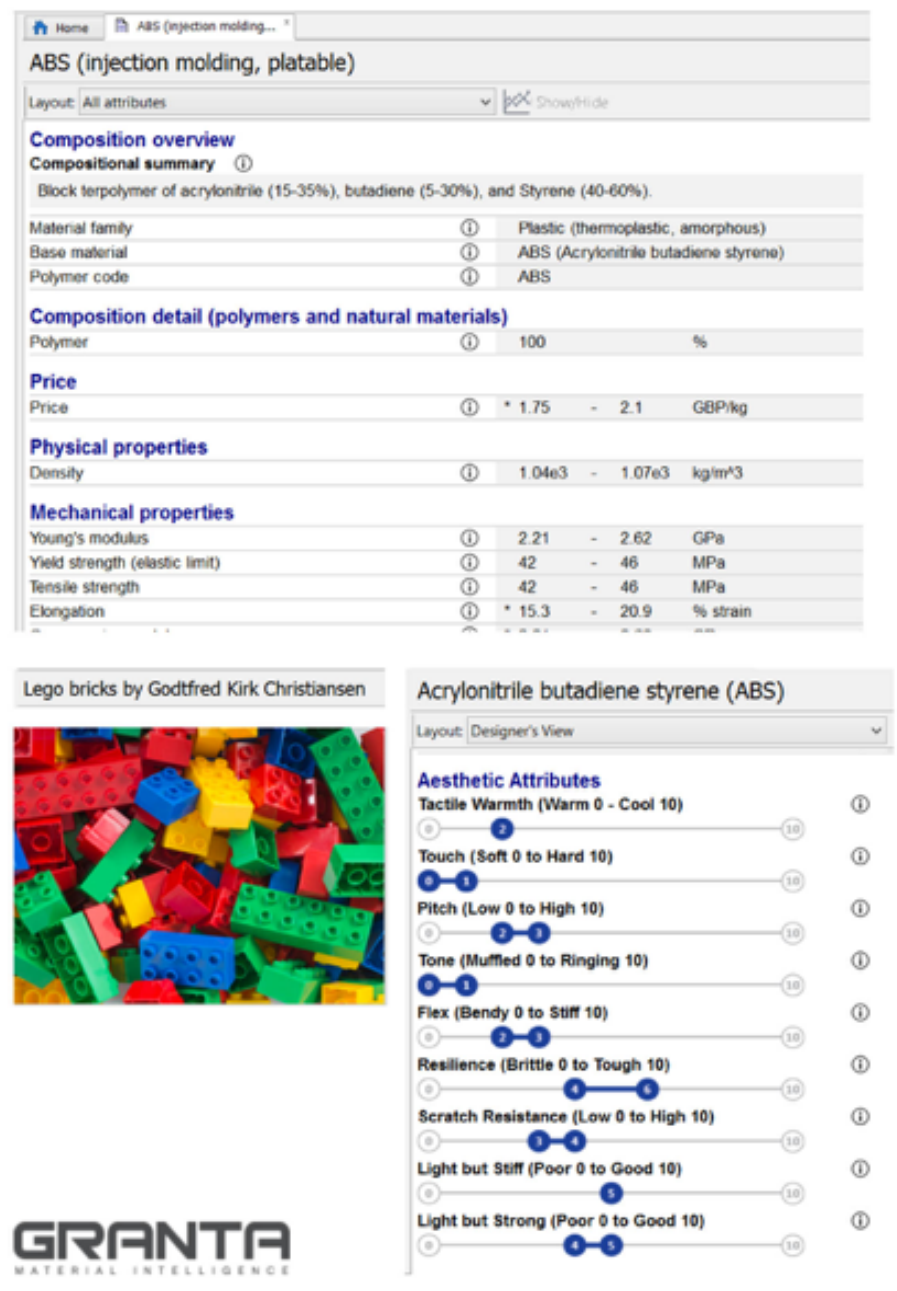

Figure 2. Granta CES Edupack materials database provides detailed engineering material properties (top), and the prototype Granta CES 'Products, Materials and Processes' database which includes design case studies and aesthetic or experiential material properties (bottom).

Intangible and sensorial characteristics are becoming increasingly important considerations in material selection. Physical collections of materials provide the benefit of being able to handle samples and experience their tactile and aesthetic properties beyond what is possible through datasheets, catalogues and online resources (Akin and Pedgley, 2016; Asbjørn-Sörensen, Jagtap and Warell, 2016). However, these resources often present material samples in pristine condition, or in an unquantified state of degradation following handling and exposure to light (Figure 3). The samples are usually devoid of context which limits designers' ability to appraise materials in product, interior or architectural applications and the agency of samples to demonstrate mechanical properties, such as stiffness, is limited (Wilkes et al., 2016). Material libraries also do not provide information about

\footnotetext{
${ }^{1}$ Granta Design (http://www.grantadesign.com) creates software for 'materials information management', which provides an extensive database of engineering properties of materials.
} 
extrinsic material properties, such as the influence of material thickness and form, or of combinations of materials, on how the material is experienced and how they will change with use.
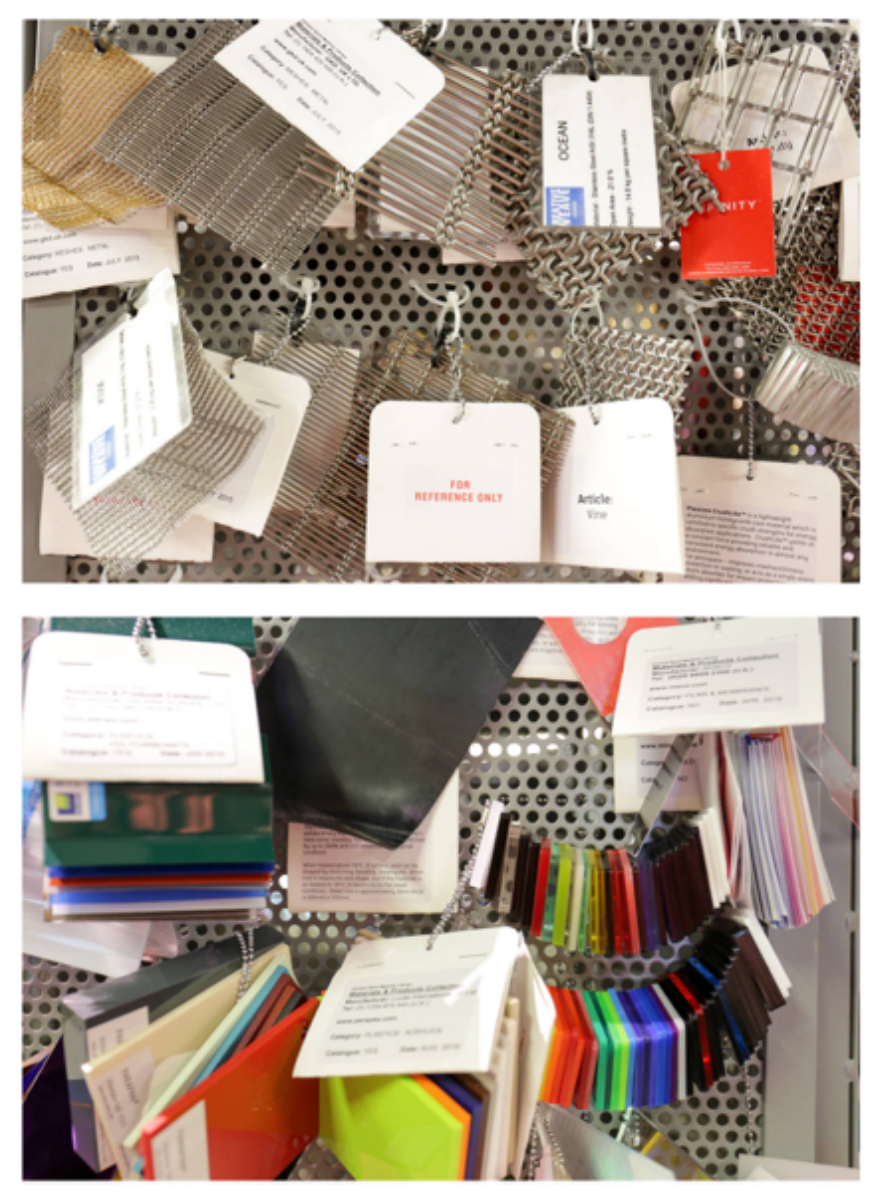

Figure 3. Pristine material samples at Central Saint Martins College of Art and Design Materials Collection, London.

To start to address these limitations the Institute of Making at University College London developed 'material-object' sets in recognizable object forms such as cubes, spheres and tuning forks, and made them in different materials "to explore the relationship between form, function and materiality" (Wilkes and Miodownik, 2018). This combination of material and form is also used in 'The Circular Material Library' (Virtanen, Manskinen and Eerola, 2017). Similarly, at Delft University of Technology, students are encouraged to create 'functional demonstrators' which integrate processed materials into product concepts (Barati et al., 2016). These hands-on material experiments attempt to "bridge the divide between 'knowledge about' and 'experience in' materials" (Pedgley, Rognoli and Karana, 2016).

It could be argued that tacit knowledge built up from personal experience observing material change in a wide range of objects equips designers to specify materials which will 'age' well in a particular application. This may be true for certain commonly used materials (e.g. it is well known that some coloured plastics will fade in ultraviolet light, and that many species of wood will become grey when exposed to external weathering), but tacit understanding is hampered by the complex web of factors that influence how a material will change in use, including the vast number of material variants and new materials, different surface finishes, different manufacturing processes and so on. The advent of DIY ("do-it-yourself") materials (Rognoli et al., 2015; Ayala Garcia, Rognoli and Karana, 2017), morphing smart materials (Studart and Erb, 2014; Holstov, Bridgens and Farmer, 2015; Oliver, Seddon and Trask, 2016) and bio-based materials which are designed to degrade (Soroudi and Jakubowicz, 2013) further complicates matters as designers have not experienced how these materials will change with use, and 
in many cases their durability and degradation have not been studied in detail (Barati et al., 2016). Furthermore, existing test methods may not be applicable and data on user responses to these materials is limited or non-existent.

\section{Resource development}

The authors propose that material change could be better exploited as a tool in the context of designing for the circular economy, if better resources were available for designers to understand the processes and results of material change. Not surprisingly, it has been found that a combination of physical material samples and detailed written information is the most effective way to learn about materials: "Industrial designers gain best understanding of materials by handling physical material samples in combination with material selection software offering both technical properties and intangible characteristics" (Asbjørn-Sörensen, Jagtap and Warell, 2016). To address the shortcomings of existing resources and provide tools which will effectively increase designers' material literacy, particularly with respect to material change, a range of resources, both physical and virtual, combining material samples with contextual case studies, were developed. The first step in creating these resources was to establish an understanding of how materials change in use, and how these changes are perceived.

\subsection{A framework for understanding material change in product design}

An understanding of material 'durability', i.e. how a material changes in response to a wide range of physical, chemical and biological stimuli, is essential in understanding how material change will influence the lifespan of a product. But this is not enough. A combination of material changes, interwoven over time, combine to create a surface 'patina' that discloses the life of an object. There is a dichotomy in how this patina is interpreted; it can result in dissatisfaction or allow an emotional bond to be forged with the object (DeSilvey, 2006; Giaccardi et al., 2014; Baxter, Aurisicchio and Childs, 2016). Chapman (2013) states that: "It is important to note here that patina is not an issue to do with material resilience or durability, but rather, a societal preoccupation with what an appropriate condition is for certain typologies of material and objects to be in".

A framework is proposed to illustrate the relationship between use and perceptions of new and 'changed' materials. The framework is based on the pioneering work of Crilly who provided a conceptual framework for understanding consumer response to product visual form (Crilly, Moultrie and Clarkson, 2004), combined with more recent work on 'materials experience' exemplified by Karana et al.'s (2015) 'Material Driven Design' methodology and wider contributions described in the Materials Experience book (Karana, Pedgley and Rognoli, 2013). These works provide a basis for understanding the factors which influence a person's response to a particular material in a particular product. We have extended this work by considering the condition of the object, how its condition will change with use, and how this will influence people's response to that object (Figure 4). 


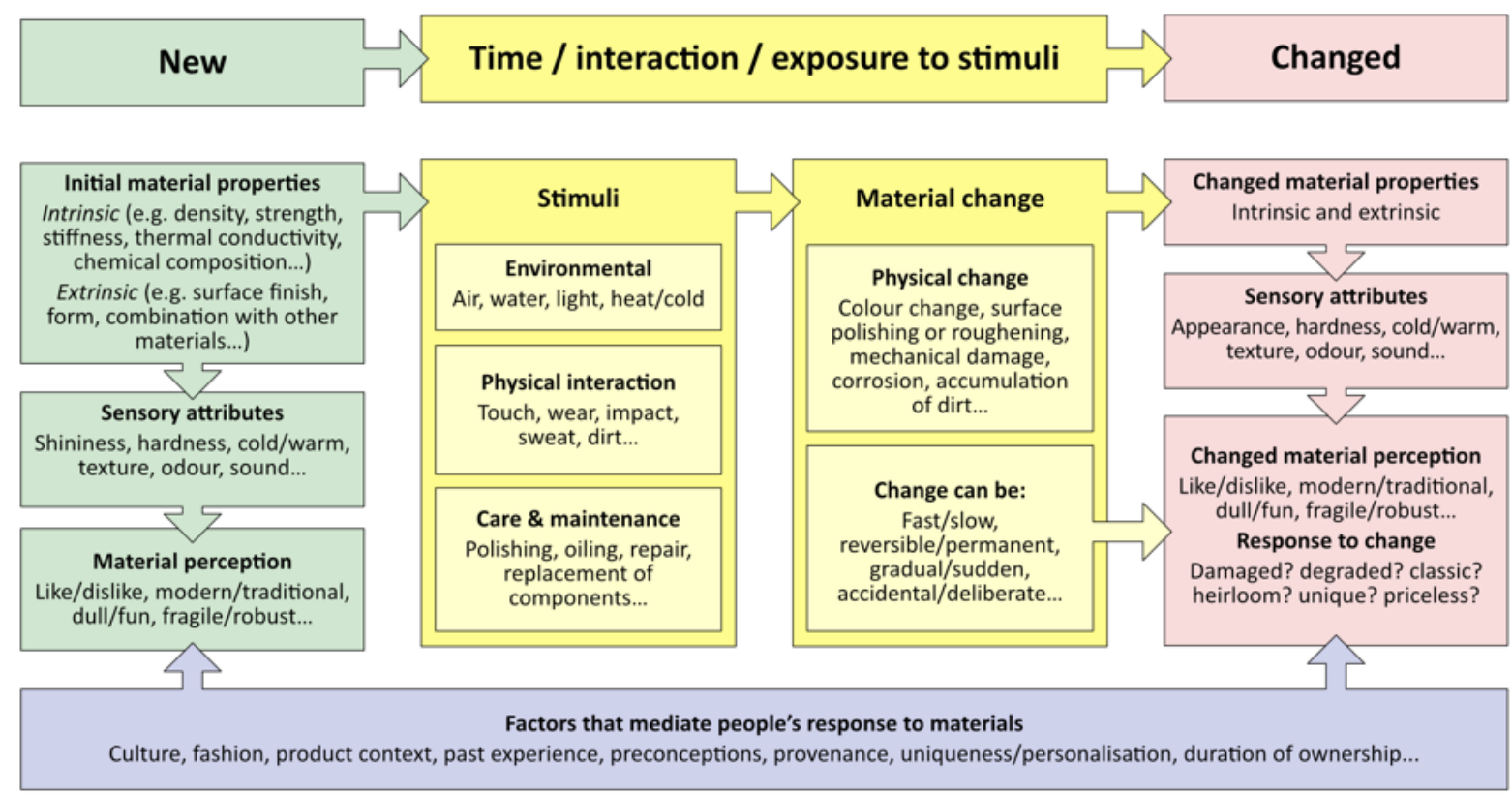

Figure 4. Framework for understanding material change in product design, showing interaction of material type, intrinsic and extrinsic properties, stimuli, and physical material changes, and experiential responses to those changes.

Materials engineering is required to understand how the choice of materials (intrinsic properties), and the specific application of these materials in a product (extrinsic properties) combine with an array of stimuli to produce changes to the material surface. Material properties, such as surface roughness, thermal conductivity and hardness, can be used to give an indication of sensory attributes, i.e. how the object will look and feel, and even how it will smell, sound (when struck) and taste (Barnes et al., 2004; Skedung et al., 2011; Wongsriruksa et al., 2012; Ashby and Johnson, 2013). But there is a further step to move from sensory attributes to people's perception of the material: how does it make them feel? What is their emotional response to the material, and to the object of which it is part? (Chapman, 2005; Mugge, Schoormans and Schifferstein, 2005; Karana, Hekkert and Kandachar, 2010; Manley et al., 2016).

For a new product, there is a complex set of interacting factors that mediate the owner's emotional response, including cultural influences, fashion, expectation, product context, past experience and preconceptions, provenance and duration of ownership, and uniqueness and personalisation. For older products that have undergone material change, these factors are still valid, but are joined by a further set of considerations:

- Has the owner spent time caring for the object, repairing, cleaning and maintaining it (Gregson, Metcalfe and Crewe, 2009; Salvia et al., 2015)?

- How did the changes to the object's surface occur - rapidly or gradually; accidentally, deliberately, or during a memorable event (for example during a particular sporting event) (Odom and Pierce, 2009; Manley, Lilley and Hurn, 2015a)?

- Are the changes reversible or permanent?

- How do the changed sensory attributes compare to the original condition of the object (Pedgley et al., 2018)?

These myriad factors combine to demarcate the elusive difference between wear, damage, degradation, graceful ageing and meaningful patina. Understanding these factors is vital to enable designers to create enduring (as opposed to durable) objects. For example, it has been observed previously that natural materials are more commonly perceived to improve with use than synthetic materials such as plastics: "Some materials 'degrade' while others 'mature' by maintaining or improving certain qualities. The positive term of maturity is usually used for natural materials such as stone, paper, 
wood, and leather, which over the years can acquire scents, colours, and textures: characteristics that far from diminishing their quality, instead acquire an aura of antiquity and preciousness" (Rognoli and Karana, 2014). And in contrast: "Plastics cease to be pristine, and become evidently worn, in a particular way. They do not patinate; they gather dirt rather than "charm," and then may elicit particularly strong feelings of disgust" (Fisher, 2004).

\subsection{Simulating material change}

To study people's response to materials that are worn or changed, to create resources to improve designers' understanding of material change, and to facilitate the development of material surfaces which age in particular ways, it is necessary to physically simulate material change and then evaluate user's attitudinal responses towards these 'changed' materials. Accelerated ageing is standard practice in many industries from wear testing of prosthetic joints to artificial weathering of construction materials, but there are no test methods for assessing the aesthetic and tactile changes of products in response to normal use, and very limited published work about how people physically interact with products.

To create prototype resources for designers which show how materials change with use, a selection of commonly used materials (aluminium, brass, copper, mild steel, stainless steel, carbon fibre composite, English oak, European beech and polypropylene) were exposed to a range of 'stimuli' including ultraviolet light, water and salt, and abrasion. All test samples were $90 \mathrm{~mm} \times 90 \mathrm{~mm}$ flat samples of sufficient thickness to be robust enough not to bend or dent during testing (typically 5 to $10 \mathrm{~mm}$ thick depending on the material).

Abrasion testing was carried out to simulate 'severe use', for example carrying an object in a pocket with keys and coins or dropping the object, using a technique developed previously (Bridgens et al., 2015, 2017; Lilley et al., 2016) which involves placing the material sample in a $100 \mathrm{~mm}$ cube sealed box with small metal objects (keys, coins, $8 \mathrm{~mm}$ nuts and bolts) and rotating the box such that the objects slide across and impact the material sample. This 'tumbling machine' operated at a rate of 3000 rotations per hour. The samples were removed from the box, cleaned, and images were taken at intervals throughout the test.

Prolonged exposure to daylight was simulated by placing the samples $30-40 \mathrm{~mm}$ away from an array of $25 \mathrm{~W}$ UV-C bulbs with peak emission wavelength of $254 \mathrm{~nm}$, for a maximum of 300 hours. Sunlight consists of a wide spectrum of visible and ultraviolet light, predominantly UV-A with some UV-B, and a minimum wavelength around $300 \mathrm{~nm}$. The short wavelength UV-C used for this test is not representative of sunlight, but UV-C is far more damaging than sunlight and can therefore accelerate material change (Haillant, 2011). However, care must be taken as some material change mechanisms will only occur at specific wavelengths and may require visible light in addition to ultraviolet. The samples were removed and imaged at intervals during the test.

Water and salt were applied to accelerate corrosion of metals, and to simulate the effect of sweat (for example for sports equipment) or of a marine environment (for architectural applications, or products used in or near the sea). Samples were sprayed with water, and fine salt (sodium-chloride) crystals were sprinkled on the surface. They were regularly sprayed with water to ensure the surface remained moist. Before obtaining each set of images the salt residue was wiped from the surface and then dried.

Acquiring consistent, high quality images of material samples is not straightforward. For photographic images, care must be taken to ensure constant lighting conditions, and reflections from shiny samples can be very difficult to avoid, requiring different lighting conditions for different materials. Instead, an approach was used which is gaining popularity for scientific imaging (Göröcs and Ozcan, 2014), which is use of a high quality flat-bed scanner (for this work an Epson Perfection V800 photo scanner). This ensures consistent lighting, avoids reflections, and can provide very high-resolution images (up to $4800 \mathrm{dpi}$ ) at low cost compared to high quality cameras and lighting. For each stimulus a series of 
images was acquired to show the effects of the material change process (Figure 5). The series of images were then combined to create video files to better illustrate the material transformation (refer to supplementary information for example videos).
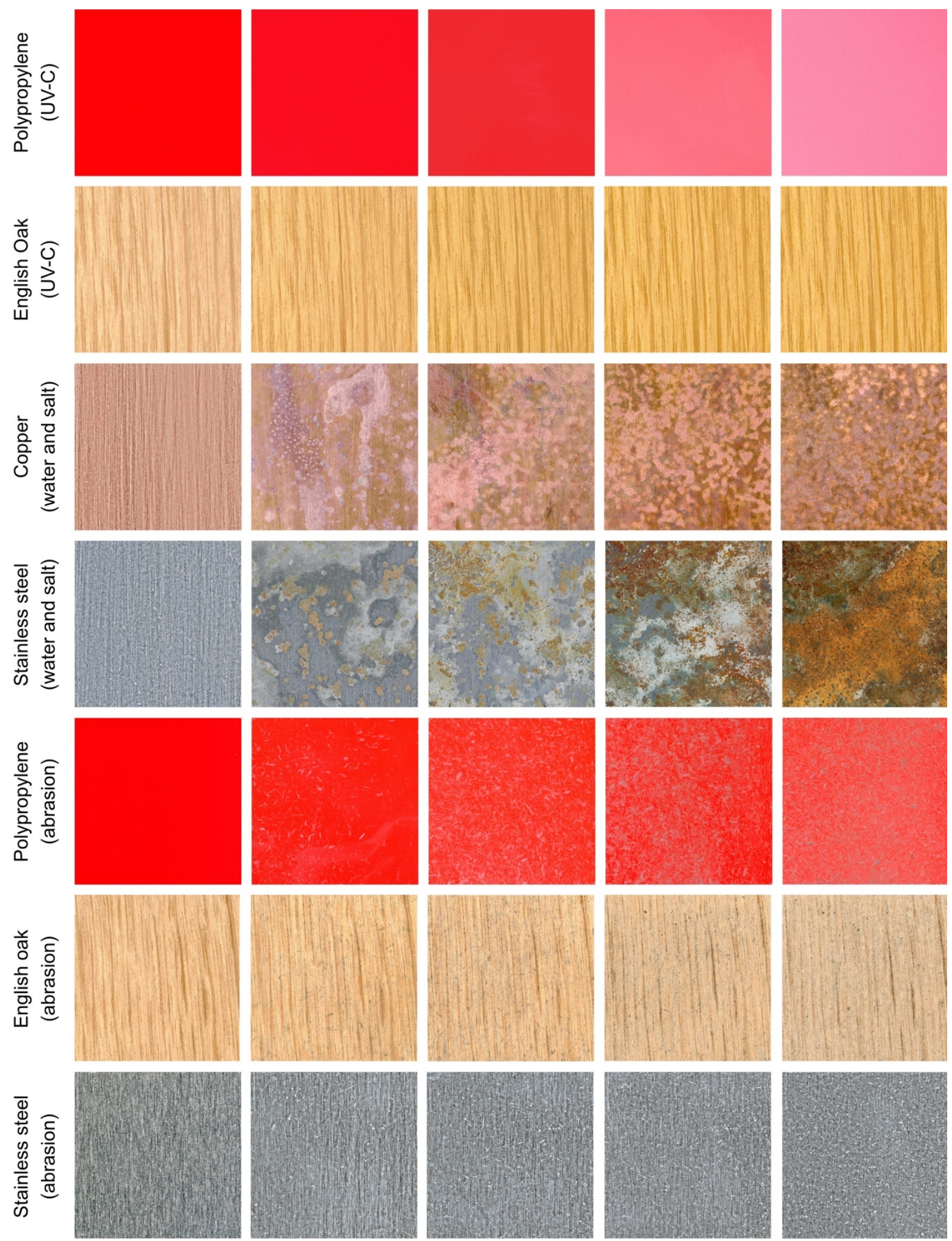

New

Time / use 
Figure 5. Images of $30 \mathrm{~mm} \times 30 \mathrm{~mm}$ areas of material samples subjected to ultraviolet light, water and salt, and abrasion. In each case the new sample is on the left, with progressively greater exposure to the stimulus towards the right. The right-hand images show 300 hours of UV-C exposure from a $25 \mathrm{~W}$ bulb at a distance of 30-40mm; 150 hours exposure to water and fine salt (sodium-chloride) crystals; and 95 minutes of tumbling at a rate of 3000 cycles per minute.

These images show what may happen to a material in use, and have potential to provide inspiration for designers, but they do not accurately predict how a particular object will change in use. A previous study by the authors (Bridgens et al., 2017) highlighted the difficulties inherent in simulating material change for particular consumer products. People's physical interaction with objects has not been studied in detail and will vary widely across different product types and different individuals. The result is a high level of variability in what will happen to any given object in use. This makes it very difficult to state that a given test method will simulate a specific period of use for a particular product.

Another challenge is to tailor the test method to a particular material and use. In the testing described above, the choice of which materials were tested with each method was made based on prior knowledge of how the materials would respond. For example, the metals were not exposed to ultraviolet light as it was known that it would not affect them, and conversely salt and water was only applied to the metals. For new materials a wide range of tests would need to be applied to establish relevant stimuli and resulting material changes. Furthermore, the generic tests described above do not account for the very specific conditions which allow certain materials to change in ways that are widely considered to be beneficial. For example, leather responds well to gentle flexing to soften the material, ideally combined with polishing and oiling. Many species of wood, including oak and larch, develop a silvery grey colour over a period of months, and the texture of the grain becomes accentuated over many years, when exposed externally to a combination of wetting, drying, oxygen and ultraviolet light. There is a risk that generic test methods, when applied to new and existing materials, will show that they 'age disgracefully', because the correct combination of stimuli has not been applied for that particular material.

\subsection{Understanding users' attitudinal responses to 'changed' materials}

To create long-lasting emotional attachment to possessions, or increase acceptance of shared or leased objects, designers need to consider the semantic cues expressed by different materials, and the emotions or attitudes they stimulate, at different stages of their lifetime. Several studies have sought to understand the complex factors which inform users' attitudinal and emotional responses to materials (Barnes et al., 2004; Wastiels et al., 2012; Wongsriruksa et al., 2012; Spence et al., 2016). These investigations tend to use semantic differential scales (Osgood, 1964) to evaluate a selection of materials via aesthetic and tactile appraisals. Materials are typically presented as new, uniformly sized sample swatches devoid of product context, and few studies have sought to probe attitudinal responses to aged materials. The lack of published data on user's responses to materials which 'age gracefully' or objects which show 'traces of use', acts as a barrier to using material change as a strategy to design for longevity and/or circularity.

'Graceful ageing' is portrayed as a positive aesthetic attribute of natural and selected man-made materials within certain niche products and their marketing materials (Figure 6). lameco computers "get better with age" as the wood "matures" to create a unique patina; 'Nylund' leather products "grow and age gracefully", and over time "bear the signs of a life with you"; Designtree lighting "age[s] gracefully so people can develop rewarding and lasting relationships with [it]"; Egg Collective employ " "live' metal finishes [which] change over time, picking up traces of the environment, and people, around them. Oxygen, water, oils, and fingerprints are recorded in the surface, making each piece unique over time"; and Paloform concrete fire-pits are "left raw with no coatings or surface treatments [to] ensure that they will age gracefully and honestly, gradually exposing more of the material's character". 

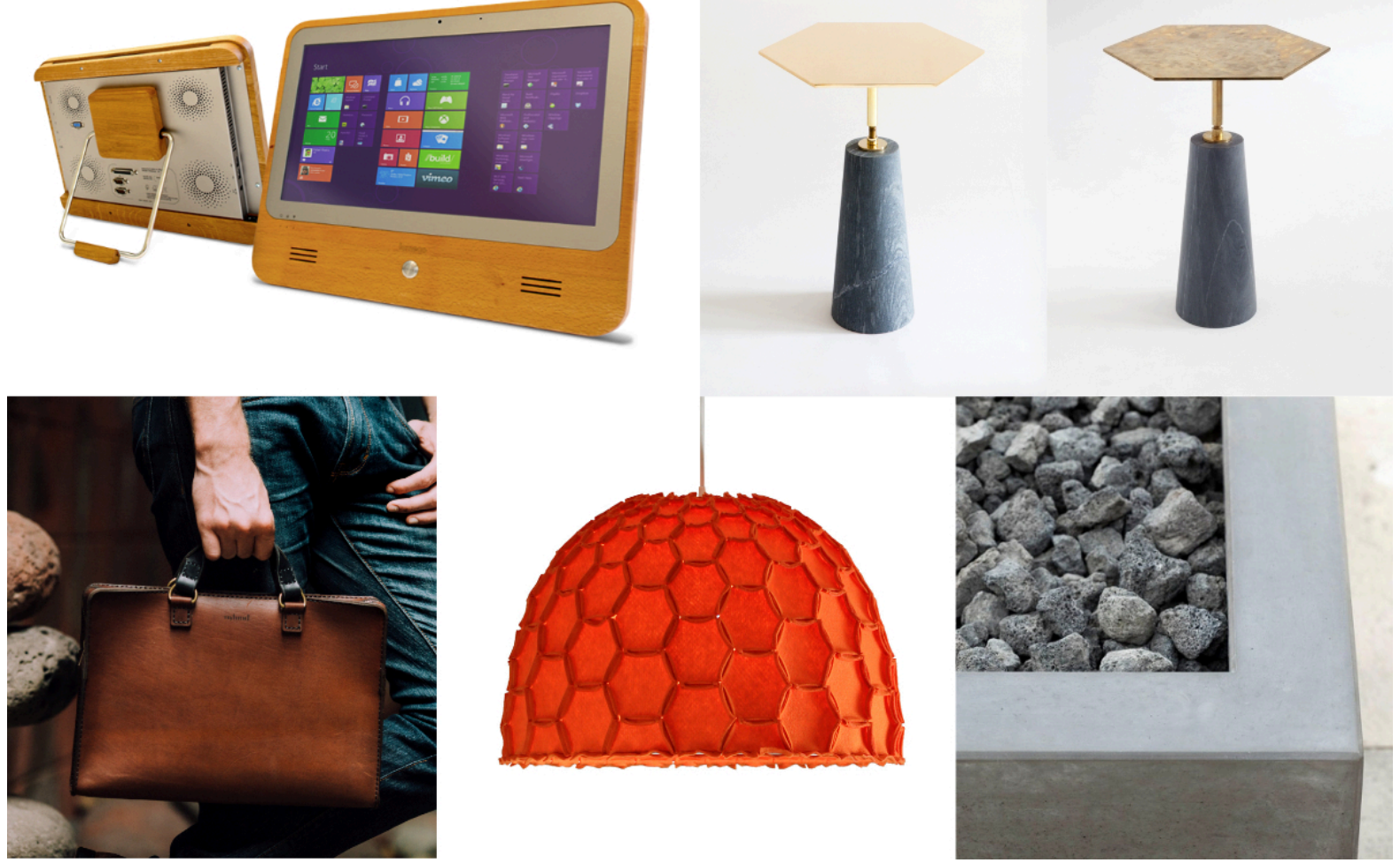

Figure 6. Examples of products with material surfaces that are designed to age gracefully (clockwise from top left): lameco v.3 touch screen computer is housed in a solid oiled ash, maple or beech case

(http://www.iameco.com); Egg Collective Hawley Side Table made from unsealed polished brass with marble base (www.eggcollective.com/); Paloform concrete firepits are "cast solid and left raw with no coatings or surface treatments. As concrete is porous, moisture can penetrate slightly into the surface causing tiny chemical changes and crystallizations, creating evidence of age and weathering" (https://paloform.com/); Designtree Nectar lampshade made from $100 \%$ recycled and recyclable PET (approximately $90 \%$ post-consumer waste), selfassembled (www.designtree.co.nz); Nylund Briefcase in vegetable-tanned top-grain cowhide, seams stitched with waxed polyester thread, beeswax and polished bone used to finish edges (http://nylunddesign.com.au).

To understand where the 'tipping point' between patination and degradation lies, to investigate which aesthetic and tactile material changes are valued, if worn natural materials are more favourably judged than their man-made counterparts, and whether material change can engender emotional attachment, a series of user perception studies was conducted (Manley, Lilley and Hurn, 2015a; Lilley et al., 2016; Manley et al., 2016; Bridgens et al., 2017). Through this research, it became apparent that designing studies which aim to uncover perceptions of aged materials is challenging and that flaws in the study design can limit their effectiveness. The appraisal of artificially aged or 'worn' materials formatted as sample discs or squares devoid of a product context, outside the confines of ownership resulted in a visceral response in which value judgements were made 'in the moment' based on a relatively rapid 'look and feel'. Perceptions alter when these materials are embodied within an object that is owned, and the passing of time can enable acclimatisation to, or even appreciation of surface changes. Thus, two longitudinal studies, one with owned objects (Manley, 2018) and one with a material coating designed to age spectacularly (Bridgens et al., 2017) were devised to allow the effect of context and acclimatisation to gradual change to be studied.

The need for longitudinal appraisals of material change in specific product categories with invested participants is apparent, yet this type of study is often prohibited by short term research funding and difficulties in participant retention. This, coupled with the relatively short lifespan of consumer goods which embody materials assumed to elicit feelings of disgust when aged such as plastic, renders their long-term study problematic. These early studies indicate that the rate of material change is an important variable informing user response to material change. 
Sudden changes, for example the first scratch on a pristine manufactured surface, elicit negative reactions due to the sudden, jarring change in the product appearance. Gradual changes, such as buildup of accumulated dirt or abrasion, allow time for acclimatization and are more likely to be perceived neutrally or positively (Manley, Lilley and Hurn, 2015a). This may give a clue as to why natural materials are perceived as ageing better than man-made materials. Natural materials have inherently complex surface patterns and textures when new (Pye, 1968), meaning that changes to the surface are less obvious than the first scratch or dent in a flawless, mass produced plastic or metal surface. This allows natural materials time to change gradually, whilst avoiding the initial disappointment due to 'loss of newness'. The sequence in which surface changes occur is also an influencing factor. Manley et al (Manley, Lilley and Hurn, 2015a) found that following an initial distressing instance of material change, the object owner's tolerance towards subsequent incremental changes increased.

The subjective nature of the appraisals and resulting diversity in perceptions of artificially or naturally aged materials within or devoid of product context led the authors to question the usefulness of data obtained from these studies in informing the development of senso-aesthetic property indicators for inclusion in the resources at this time. However, we acknowledge the potential benefit of including qualitative material perceptions, drawn from user studies, in challenging conventional assumptions of appreciation and depreciation related to the presence or absence of 'traces of use'.

\section{Prototype resource}

\subsection{Implementation}

Based on a tentative understanding of the potential role of material change in a transition to the circular economy (section 2.1), a review of existing material resources (section 2.2), the framework for understanding material change (section 3.1), and with input from our industrial partners (Granta Design, $\mathrm{SCIN}^{2}$ and MaterialDriven ${ }^{3}$ ) a prototype resource was developed to test the feasibility of educating designers about material change using an online tool. Our research on attitudinal responses to material change (section 3.3) highlighted the challenges in making any generalisations in this area, and made it clear that inclusion of attitudinal responses was beyond the scope of our initial resource development.

Using a combination of descriptive text, tables showing material-stimuli interactions (Figure 7), image sequences and videos of physical samples exposed to a range of stimuli (Figure 5), images of objects and product case studies, prototype resources were developed with a limited number of materials for evaluation (Figure 8 and Figure 9). Information about how materials change when exposed to each stimulus was gathered from experimental work (section 3.2), textbooks (e.g. Thompson, 2017), and tacit knowledge gained from the authors' experiences of observing material change on objects and buildings. To effectively bridge the difference in disciplinary understanding between material scientists and designers (Wilkes et al., 2016) two distinct formats were chosen: an interactive app/website and a contributed database for Granta's CES Edupack Products, Materials and Processes (PMP) software. The 'contributed database' is a freely available database that can be downloaded from Granta Design's website and is viewed through the Granta CES Edupack software. The app/website contains identical information but formatted as a standalone web application. The resources were not intended to be used to specify materials but as inspiration for material selection in the early stages of design. To enable the resources to be used flexibly and to fit with many different design processes, the resources are arranged so that the user can begin either with inspirational product case studies, or by looking at specific

\footnotetext{
2 SCIN (https://www.scin.co.uk) is a material library and materials consultancy based in London, UK

${ }^{3}$ MaterialDriven (https://www.materialdriven.com) is a material library and materials consultancy based in London, UK
} 
materials, or by learning about a particular type of material change. Materials are experienced by all five senses, but primarily by touch and sight. Acknowledging the importance of language in making a resource widely accessible, rather than have resources titled 'aesthetic properties' and 'tactile properties', and to incorporate the concept of materials changing, the different types of material change are introduced with the questions: 'how will it look?' and 'how will it feel?'. To include other changes that are not strictly tactile or aesthetic, such as changes in flexibility or shape, a further question was added: 'how will it behave?'. Whichever route is taken, links are provided to all other relevant sections. For example, a product case study (e.g. the Stain teacup) contains links to the materials used within that product (ceramic) and the stimuli that cause it to change in this context (residue - the building up of dirt, sweat or other contaminants) (Figure 9, bottom right). Alternatively, a particular material (e.g. copper) provides detailed information about how that material will change, and provides links to relevant product case studies (Figure 9, bottom left). 


\begin{tabular}{|c|c|c|c|c|c|c|c|c|c|c|c|c|c|c|}
\hline \multirow{2}{*}{\multicolumn{2}{|c|}{ Material }} & \multicolumn{5}{|c|}{ Metal } & \multicolumn{4}{|c|}{ Biological } & \multicolumn{2}{|c|}{ Polymer } & \multicolumn{2}{|c|}{ Mineral } \\
\hline & & $\frac{1}{\grave{2}}$ & 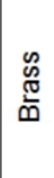 & $\begin{array}{l}\bar{\Phi} \\
\frac{\Phi}{\omega} \\
\frac{\partial}{\Sigma} \\
\frac{D}{\Sigma}\end{array}$ & 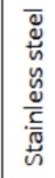 & 은 & 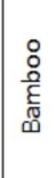 & $\stackrel{7}{\circ}$ & $\begin{array}{l}\frac{E}{C} \\
\bar{D}\end{array}$ & 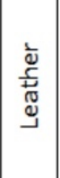 & 哭 & $\begin{array}{l}\frac{0}{0} \\
\frac{0}{2} \\
\frac{0}{0} \\
\frac{0}{2} \\
\frac{0}{0}\end{array}$ & $\frac{\frac{0}{0}}{\frac{0}{\frac{0}{0}}}$ & 岕 \\
\hline \multirow{4}{*}{ 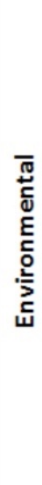 } & $\begin{array}{l}\text { Moisture: wetting due } \\
\text { to rain, exposure to } \\
\text { water or humidity }\end{array}$ & $\sqrt{ }$ & $\checkmark$ & $\sqrt{ }$ & & $\sqrt{ }$ & $\sqrt{ }$ & $\sqrt{ }$ & & & & & $\sqrt{ }$ & \\
\hline & $\begin{array}{l}\text { Oxygen: exposure to } \\
\text { air, applies to virtually } \\
\text { all use cases }\end{array}$ & $\sqrt{ }$ & $\checkmark$ & $\checkmark$ & & $\sqrt{ }$ & $\checkmark$ & $\checkmark$ & & & & & & \\
\hline & $\begin{array}{l}\text { Heat: from the sun, the } \\
\text { function of the object, } \\
\text { or from the user }\end{array}$ & \multicolumn{11}{|c|}{$\begin{array}{l}\text { Heat alone rarely induces visual changes in material } \\
\text { surfaces, but heat acts to speed up many other processes } \\
\text { of material change. }\end{array}$} & & \\
\hline & $\begin{array}{l}\text { Ultraviolet light: from } \\
\text { the sun }\end{array}$ & & & & & & $\checkmark$ & $\checkmark$ & $\sqrt{ }$ & $\checkmark$ & $\sqrt{ }$ & $\sqrt{ }$ & & \\
\hline \multirow{5}{*}{ 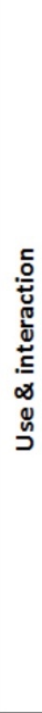 } & $\begin{array}{l}\text { Pressure or stress: } \\
\text { carrying the weight of } \\
\text { people or other objects }\end{array}$ & & & & & & & & & $\sqrt{ }$ & $\sqrt{ }$ & $\sqrt{ }$ & & \\
\hline & $\begin{array}{l}\text { Abrasion: contact with } \\
\text { hard, rough objects or } \\
\text { surfaces }\end{array}$ & $\sqrt{ }$ & $\checkmark$ & $\sqrt{ }$ & $\sqrt{ }$ & $\checkmark$ & $\checkmark$ & $\sqrt{ }$ & $\sqrt{ }$ & $\sqrt{ }$ & $\sqrt{ }$ & $\sqrt{ }$ & $\sqrt{ }$ & $\sqrt{ }$ \\
\hline & $\begin{array}{l}\text { Polishing: repeated } \\
\text { contact with smooth } \\
\text { surfaces such as fabrics }\end{array}$ & $\sqrt{ }$ & $\checkmark$ & $\checkmark$ & $\sqrt{ }$ & $\sqrt{ }$ & $\checkmark$ & $\checkmark$ & $\sqrt{ }$ & $\checkmark$ & $\sqrt{ }$ & $\sqrt{ }$ & $\sqrt{ }$ & \\
\hline & $\begin{array}{l}\text { Impact: when } \\
\text { dropped, or through } \\
\text { use (e.g. sports } \\
\text { equipment) }\end{array}$ & $\sqrt{ }$ & $\checkmark$ & $\sqrt{ }$ & $\sqrt{ }$ & $\sqrt{ }$ & & & & & & & $\sqrt{ }$ & $\sqrt{ }$ \\
\hline & $\begin{array}{l}\text { Residue: build up of } \\
\text { dirt, sweat or other } \\
\text { contaminants }\end{array}$ & & & & & & $\checkmark$ & $\checkmark$ & $\sqrt{ }$ & $\sqrt{ }$ & & & $\sqrt{ }$ & $\sqrt{ }$ \\
\hline \multirow{4}{*}{ 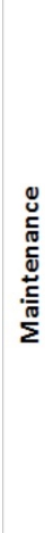 } & $\begin{array}{l}\text { Repair: includes } \\
\text { replacing components, } \\
\text { joining broken pieces }\end{array}$ & $\sqrt{ }$ & $\sqrt{ }$ & $\sqrt{ }$ & $\checkmark$ & $\checkmark$ & $\checkmark$ & $\checkmark$ & $\sqrt{ }$ & $\checkmark$ & $\sqrt{ }$ & $\sqrt{ }$ & $\sqrt{ }$ & $\sqrt{ }$ \\
\hline & $\begin{array}{l}\text { Cleaning: removal of } \\
\text { residue, often involves } \\
\text { wetting }\end{array}$ & & & & & & $\checkmark$ & $\checkmark$ & $\sqrt{ }$ & $\checkmark$ & & & $\checkmark$ & $\checkmark$ \\
\hline & $\begin{array}{l}\text { Oiling: applying } \\
\text { surface treatments } \\
\text { including oil and wax }\end{array}$ & $\sqrt{ }$ & $\checkmark$ & $\checkmark$ & $\sqrt{ }$ & $\checkmark$ & $\checkmark$ & $\checkmark$ & & $\checkmark$ & & & & \\
\hline & $\begin{array}{l}\text { Polishing: rubbing with } \\
\text { a cloth, often } \\
\text { combined with oiling. }\end{array}$ & $\sqrt{ }$ & $\checkmark$ & $\checkmark$ & $\checkmark$ & $\sqrt{ }$ & $\sqrt{ }$ & $\sqrt{ }$ & & $\sqrt{ }$ & & & $\sqrt{ }$ & \\
\hline 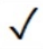 & Stimulus has a major im & pact & on th & mat & erial & $\checkmark$ & Stim & hulu & nas a & $\mathrm{mi}$ & eff & & is $m$ & terial \\
\hline
\end{tabular}

Figure 7. "How will it look?": aesthetic change material-stimuli interaction table for the selected materials which were included in the prototype resources (refer to supplementary information for equivalent 'how will it feel?' and 'how will it behave?' tables) based on material experimentation and the authors' personal experience. 


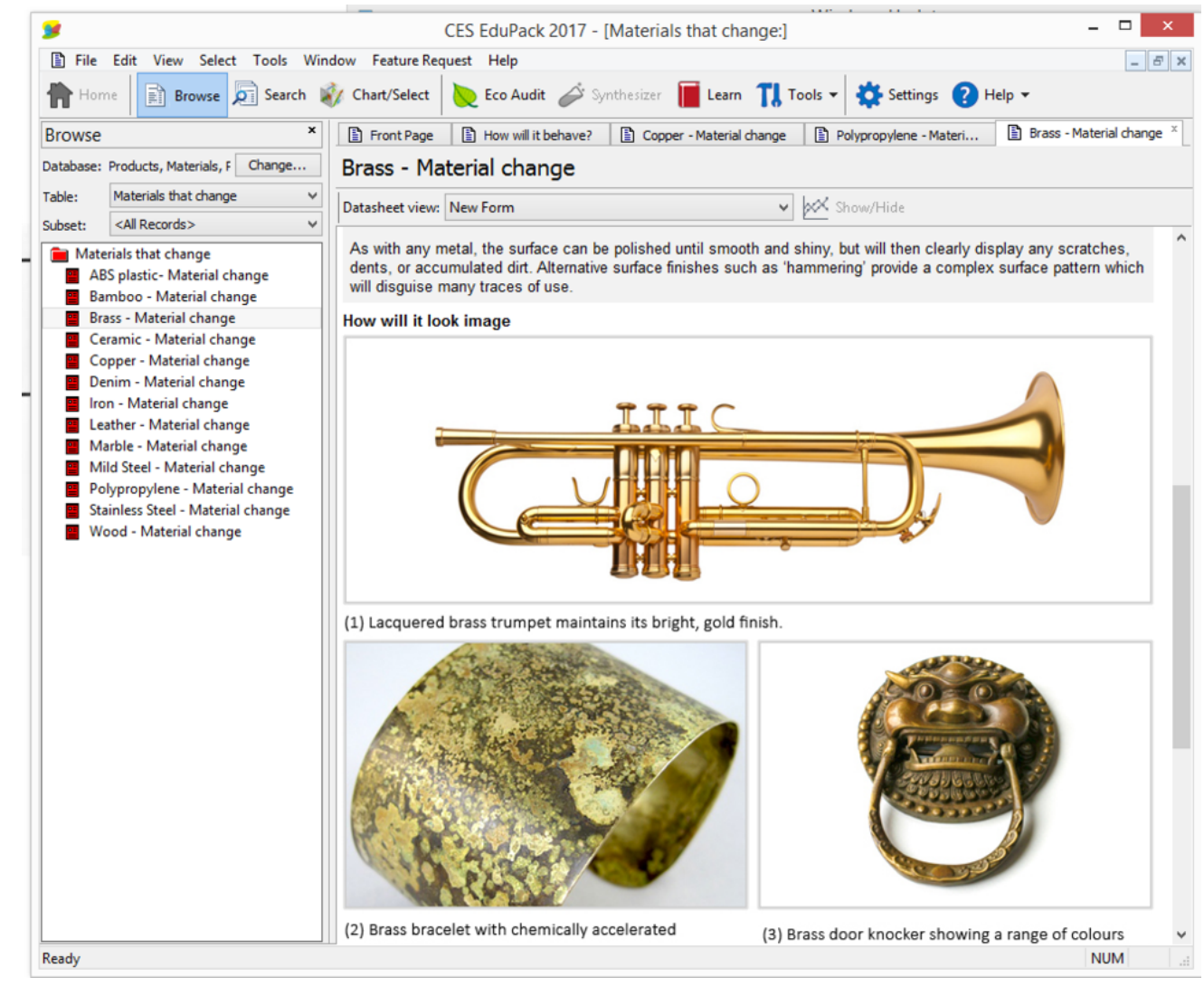

Figure 8. Prototype 'Material change' resource implemented alongside Granta's CES Edupack 'Products, Materials and Processes' database. 


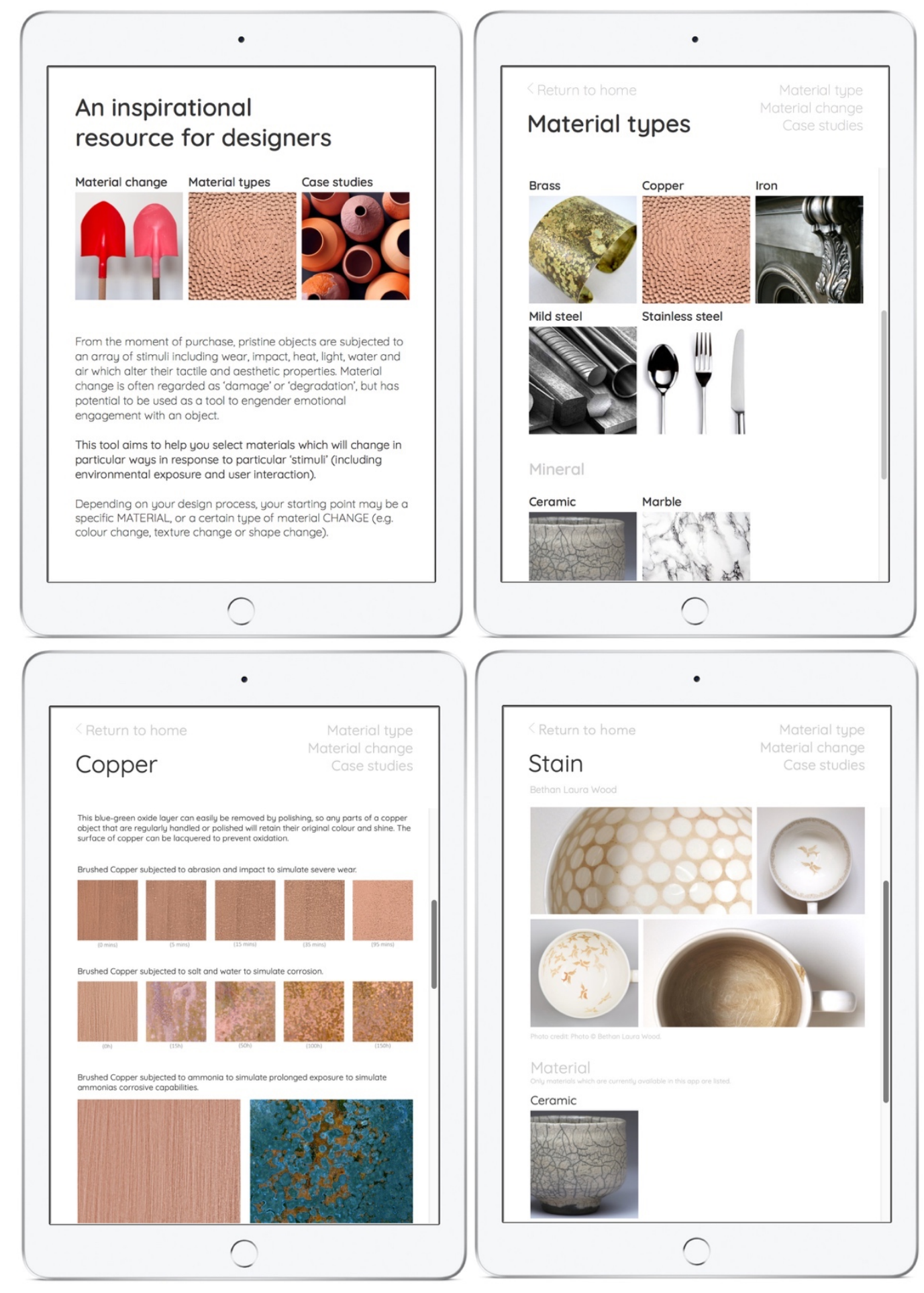

Figure 9. Material change resource implemented within a prototype app/website.

\subsection{Evaluation}

The prototype resources were evaluated by engineers, designers and architects at an evaluation workshop $(n=17)$ and via an online survey $(n=25)$. At the half-day workshop, the participants were provided with a brief introduction to the topic of material change, and access to the prototype resource in Granta CES Edupack format. They were then asked to use the resource to help them select suitable materials for two design scenarios (see supplementary information). A facilitated discussion after each scenario elicited feedback under headings of 'what were the best features?', 'what could be improved?' 
and 'what could be added?'. Participants also completed an evaluation questionnaire (full details in supplementary information). The prototype app was made publicly available and participants were encouraged to explore the resource in their own time with no set task, and then complete an online questionnaire.

The findings indicated that the inclusion of product case studies, tables showing material-stimuli interactions and time-lapse videos illustrating material change were seen as highly beneficial, however, "more images of products that have aged, rather than sample squares of the aged material" would have been preferable. This suggestion is supported by literature as designer's interactions with materials are typically through products (Ashby and Johnson, 2013) and materials' meaning is influenced by the product that they are embodied in (Karana and Hekkert, 2008). The importance of object form and usage on the appearance and distribution of patina on the surface of objects can be observed in Figure 1. However, the challenge in building a library of images of used objects is that it is difficult to establish the stimuli that the objects were exposed to throughout their lifetime. A valuable resource could be established if a collection of images (or preferably physical artefacts) could be made which included the narrative of the object's life (Odom and Pierce, 2009; Zijlema, van den Hoven and Eggen, 2017) and documented the instances when material change occurred. The V\&A (Victoria \& Albert Museum, London) exhibition 'Every Object Tells a Story' (2005), which included a user-driven, contributory website to help people recognise, understand and engage in the personal meanings and narratives that exist around and within objects, exemplifies this approach. For future research the increasing use of social media provides scope to crowd-source images and narratives of people's objects, to populate an open-source design resource.

A common request was for more detailed information about the timescales over which material change occurs e.g. "If you apply x condition over y time, this will happen". The variability in environmental stimuli, how an object is used (or abused), and the many variants of each type of material, make it very difficult to state that a given test method will simulate a specific period of use for a particular product. At best we can hope to understand approximate timescales of material change: will the material surface change over a period of seconds, hours, days, months, years, decades or centuries? The timescales really are this diverse; compare the instantaneous appearance of marks on a polished surface when it is first touched, the accumulation of scratches on a mobile phone over several months, the softening of leather which can take years, and the gradual wear of stone steps over centuries of use.

The prototype 'Material Change' Granta contributed database was set up as an independent resource which did not make use of existing data in Granta's databases. However, it was suggested that it may be beneficial to use existing functional durability data to inform material change indicators. This would be similar to the Granta "Products, Materials \& Processes" database which utilises engineering properties to calculate 'sensorial indicators' such as softness to the touch, warmth to the touch and abrasion resistance (Figure 2). A combination of durability data with surface hardness and other mechanical properties would provide an indication of which chemical and physical stimuli will affect a given material, but not the nature of the aesthetic and tactile changes which would result, which could be provided by supplementary images.

A desirable outcome from using the resource was an understanding of how to control material change within a product, along a spectrum from achieving zero material change, controlling the rate of change, introducing specific 'triggers' to enable change at a particular point in the product lifecycle, and understanding whether gradual change is inevitable. This would enable material change within a product to be better aligned to anticipated product lifetimes and circular economy strategies. Contamination, degradation and 'traces of use' can reduce the uptake of key circular economy strategies including re-use, sharing and leasing (Baxter, Aurisicchio and Childs, 2017). In the context of cars, stains, scratches, cigarette odours and sticky residues are all indicators of prior use, therefore, specification of highly durable materials with restorative self-cleaning or scratch-resistant surfaces 
(Haug, 2018) may overcome such barriers. Alternatively, triggered material change could influence the consumer to return products at optimal points in the product life cycle, for upgrade or replacement, with recovery of the original components into a closed loop (Wilson et al., 2015).

All survey respondents agreed that seeing a physical sample alongside digital information would improve their understanding of how materials feel, look, smell and behave following changes to the material surface. This presents a challenge given the large number of materials in use and the number of materials libraries that would be required to reach a significant proportion of designers, but there may be opportunities for technological solutions. The application of haptic (simulated touch) technology could offer an immersive tactile experience (Culbertson, Schorr and Okamura, 2018), or recent advances in printing textured surfaces, such as Casio's '2.5D' Mofrel printer, may enable samples to be printed as required. However, a more low-tech and affordable solution may be to pair access to digital resources with provision of a set of material samples which could be used to 'calibrate' the meaning of sensorial indicators in the software. For example, the roughness of a surface may be described on a scale of 1 to 10 in a digital resource; a set of physical samples would demonstrate to the user what these values actually feel like.

The physical world around us features a multitude of materials embodied in products, buildings and cityscapes in various states of wear, which could potentially be used as a resource for improving material literacy. To do this the viewer needs information about the materials that have been used, how they looked when new, and how long they have been in use. This could be provided using augmented reality software running on a smartphone or tablet, for example for a particular area of a city, or for a curated collection of objects.

\section{Conclusions}

A successful transition to more sustainable modes of consumption requires not only top-down initiatives but engagement and involvement of consumers. People's emotional response to the objects that they own and encounter in everyday life plays a role in the path that those objects will take through the circular economy (or not, if they elicit disgust or disappointment and are disposed of). If material change is considered during the design phase in tandem with form, use, ergonomics and operating environment, then it may be possible to design for a particular form of material change and guide products into sustainable patterns of use, care, maintenance and reuse: "patina is a necessary design consideration to assist the extension of product life spans in graceful and socially acceptable ways" (Chapman, 2013). However, we have identified multiple challenges which must be addressed to make this design concept a reality.

A framework has been presented which is intended to provide a tool which can be used to combine information from multiple sources to better understand the interaction of how products are used, how materials change in response to stimuli, and how people will respond to those changes (Figure 3). In each of these areas further work is required to provide sufficient information to enable this tool to be used in the design process. Designing for material change requires that designers grapple with great uncertainty. People's physical interaction with objects is poorly understood and highly variable, as are external environmental stimuli. Designed material change will need to be robust to these uncertainties, or better this variability can be utilised to make products that change in unique and unpredictable ways, potentially increasing their emotional value through personalisation.

The need for easily accessible information about how materials change is becoming increasingly urgent as myriad new materials such as fibre reinforced composites, bioplastics and 'DIY materials' are developed, for which designers lack any tacit knowledge of how they will change. Accelerated 'wear and tear' testing should enable more rapid, lower risk, adoption of new materials in products. However, 
even if people's physical interaction with products was better understood, and suitable accelerated ageing tests could be developed to accurately simulate 'wear and tear', a generic test is unlikely to achieve 'graceful ageing' as the stimuli required are different for each material and may require a combination of stimuli over varying timescales.

We have developed and evaluated prototype inspirational design resources to increase designers' knowledge of material change. The feedback demonstrated that designers welcome these resources as they provide information that is not available elsewhere and combine textual information with material and product images, in a highly cross-referenced format. The prototype elicited constructive feedback: further development is required to increase the range of materials considered, and to improve information about rates of change: what are the timescales for material change? How can material change be accelerated, slowed down, halted, or triggered at a particular point in the product lifecycle? This understanding of timing and control is crucial to enable material change to be aligned with a particular circular economy strategy.

\section{Acknowledgments}

The authors would like to thank the UK Engineering and Physical Sciences Research Council who provided all funding for this work as part of ENDURE (Enabling Designers to Understand Material Change, EPSRC Impact Acceleration Account) and CLEVER (Closed Loop Emotionally Valuable Ewaste Recovery project, EP/K026380/1), and Granta Design (https://www.grantadesign.com), SCIN (https://www.scin.co.uk) and MaterialDriven (https://www.materialdriven.com) who provided access to their materials specification resources and supported our resource development and evaluation.

\section{References}

Akin, F. and Pedgley, O. (2016) 'Sample libraries to expedite materials experience for design: A survey of global provision', Materials \& Design, 90. doi: http://dx.doi.org/.

Asbjørn-Sörensen, C., Jagtap, S. and Warell, A. (2016) 'Material selection in industrial design education - a literature review', International Conference on Engineering and Product Design Education. Aalborg University, Denmark. Available at: internal-pdf://0304089160/Sörensen-2016International Conference on Engi.pdf LB - material selection.

Ashby, M. and Johnson, K. (2013) Materials and design: the art and science of material selection in product design. Butterworth-Heinemann. Available at: internal-pdf://0719885356/Ashby-2013.pdf LB material selection.

Ayala Garcia, C., Rognoli, V. and Karana, E. (2017) 'Five Kingdoms of DIY Materials for Design', in International Conference 2017 of the Design Research Society Special Interest Group on Experiential Knowledge (EKSIG). TUDelft Open, pp. 222-234. Available at: internalpdf://228.60.152.10/EKSIG2017_CAG_VR_EK.pdf LB - DIY materials.

Bakker, C. et al. (2014) 'Products that last', Product Design for Circular Business Models.

Ball, A. D. and Tasaki, L. H. (1992) 'The Role and Measurement of Attachment in Consumer Behavior', Journal of Consumer Psychology, 1(2), pp. 155-172. Available at: internalpdf://209.155.80.8/Ball-1992-Journal of Consumer Psychology.pdf LB - emotionally durable design.

Barati, B. et al. (2016) 'Functional Demonstrators to Support Understanding of Smart Materials', in Proceedings of the TEl'16: Tenth International Conference on Tangible, Embedded, and Embodied Interaction. ACM, pp. 386-391. Available at: internal-pdf://0719885355/Barati-2016-Proceedings of the TEl'16_ Tenth I.pdf LB - material selection.

Bardhi, F. and Eckhardt, G. M. (2012) 'Access-based consumption: The case of car sharing', Journal of Consumer Research, 39(4), pp. 881-898. Available at: internal-pdf://0719885352/Bardhi-2012Journal of Consumer Research.pdf LB - Circular economy.

Barnes, C. J. et al. (2004) 'Surface finish and touch-a case study in a new human factors tribology', Wear, 257, p. 740. Available at: internal-pdf://93.199.158.167/C.J. Barnes-2004-Wear.pdf LB - 
material perception.

Baxter, W., Aurisicchio, M. and Childs, P. (2017) 'Contaminated Interaction: Another Barrier to Circular Material Flows', Journal of Industrial Ecology, 21(3), pp. 507-516. Available at: internalpdf://228.60.152.24/Baxter-2017-Journal of Industrial Ecology.pdf LB - Circular economy.

Baxter, W. L., Aurisicchio, M. and Childs, P. R. N. (2016) 'Materials, use and contaminated interaction', Materials \& Design, 90, pp. 1218-1227. doi: http://dx.doi.org/.

Bridgens, B. et al. (2015) 'Ageing gracefully to increase product longevity', PLATE: Product Lifetimes and The Environment. Nottingham Trent University.

Bridgens, B. et al. (2017) 'Closing the Loop on E-waste: A Multidisciplinary Perspective', Journal of Industrial Ecology. doi: 10.1111/jiec.12645.

British Standards Institution (2017) 'BS 8001:2017. Framework for implementing the principles of the circular economy in organizations - Guide'. bsi. Available at: internal-pdf://65.167.196.192/British Standards Institution-2017.pdf LB - Circular economy.

Candy, F. et al. (2004) 'Temporal Transformation of Materials: Can Designers Harness the Effects of Time to Create a Contemporary Aesthetic of "Worldliness" within New Products?', 4th International Conference on Design and Emotion. Edited by P. M. A. Desmet et al. Ankara, Turkey. Available at: internal-pdf://114.90.6.250/Candy-2004-4th International Conference on Des.pdf LB - material ageing.

Carr, C. and Gibson, C. (2015) 'Geographies of making: Rethinking materials and skills for volatile futures', Progress in Human Geography, 40(3), pp. 297-315. doi: 10.1177/0309132515578775.

Chapman, J. (2005) Emotionally durable design: objects, experiences and empathy. Earthscan. Available at: internal-pdf://0084353894/Chapman-2005.pdf LB - emotionally durable design.

Chapman, J. (2013) 'Meaningful Stuff: Towards longer lasting products', in Karana, E., Pedgley, O., and Rognoli, V. (eds) Materials Experience: fundamentals of materials and design. ButterworthHeinemann, pp. 135-143. Available at: internal-pdf://226.187.217.89/Chapman-2013-Materials Experience_fundamental.pdf LB - emotionally durable design.

Chapman, J. (2015) 'Hadal or epipelagic? The depths, and shallows, of material experience', Product Lifetimes And The Environment, p. 57. Available at: internalpdf://0719885324/PLATE_2015_proceedings.pdf.

Charter, M. and Tischner, U. (2017) Sustainable solutions: developing products and services for the future. Routledge.

Connor-Crabb, A., Miller, K. and Chapman, J. (2016) 'Design Strategies for the Eternal Reoccurrence of the New', Fashion Practice. Available at: internal-pdf://0719885378/Connor-Crabb-2016-Fashion Practice.pdf LB - longevity and optimal lifetimes.

Cooper, T. (2005) 'Slower Consumption: Reflections on Product Life Spans and the "Throwaway Society"', Journal of Industrial Ecology, 9(1-2), pp. 51-67.

Cooper, T. (2016) Longer lasting products: alternatives to the throwaway society. CRC Press.

Crilly, N., Moultrie, J. and Clarkson, P. J. (2004) 'Seeing things: consumer response to the visual domain in product design', Design studies. Elsevier, 25(6), pp. 547-577. Available at: internalpdf://189.27.88.145/Crilly-2004-Design studies.pdf LB - Design methods.

Culbertson, H., Schorr, S. B. and Okamura, A. M. (2018) 'Haptics: The Present and Future of Artificial Touch Sensation', Annual Review of Control, Robotics, and Autonomous Systems, (0).

DeSilvey, C. (2006) 'Observed decay: telling stories with mutable things', Journal of material culture, 11(3), pp. 318-338. Available at: internal-pdf://189.27.88.164/DeSilvey-2006-Journal of material culture.pdf LB - material ageing.

Edbring, E. G., Lehner, M. and Mont, O. (2016) 'Exploring consumer attitudes to alternative models of consumption: motivations and barriers', Journal of Cleaner Production, 123, pp. 5-15. doi: 10.1016/j.jclepro.2015.10.107.

European Commission (2015) Closing the loop - An EU action plan for the Circular Economy. Brussels: European Commission. Available at: internal-pdf://189.27.88.169/European Commission- 
2015.pdf LB - Circular economy.

Fisher, T. H. (2004) 'What We Touch, Touches Us: Materials, Affects, and Affordances', Design Issues, 20(4), pp. 20-31. Available at: internal-pdf://195.108.97.36/Fisher-2004-Design Issues.pdf LB - emotionally durable design.

Giaccardi, E. et al. (2014) 'Growing traces on objects of daily use: a product design perspective for HCl', in Proceedings of the 2014 conference on Designing interactive systems. ACM, pp. 473-482. Available at: internal-pdf://121.226.169.217/Giaccardi-2014-Proceedings of the 2014 confere.pdf LB material ageing.

Göröcs, Z. and Ozcan, A. (2014) 'Biomedical Imaging and Sensing using Flatbed Scanners', Lab on a chip, 14(17), pp. 3248-3257. doi: 10.1039/c4lc00530a.

Gregson, N., Metcalfe, A. and Crewe, L. (2009) 'Practices of Object Maintenance and Repair How consumers attend to consumer objects within the home', Journal of Consumer Culture, 9(2), pp. 248272. Available at: internal-pdf://121.226.169.206/Gregson-2009-Journal of Consumer Culture.pdf LB repair.

Haas, W. et al. (2015) 'How Circular is the Global Economy?: An Assessment of Material Flows, Waste Production, and Recycling in the European Union and the World in 2005', Journal of Industrial Ecology, 19(5), pp. 765-777. doi: 10.1111/jiec.12244.

Haillant, O. (2011) 'Accelerated weathering testing principles to estimate the service life of organic PV modules', Solar Energy Materials and Solar Cells, 95(5), pp. 1284-1292.

Haug, A. (2018) 'Defining "resilient design"in the context of consumer products', The Design Journal, 21(1), pp. 15-36.

Hobson, K. (2015) 'Closing the loop or squaring the circle? Locating generative spaces for the circular economy', Progress in Human Geography, 40(1), pp. 88-104. doi: 10.1177/0309132514566342.

Hobson, K. and Lynch, N. (2016) 'Diversifying and de-growing the circular economy: Radical social transformation in a resource-scarce world', Futures, 82, pp. 15-25. Available at: internalpdf://189.27.88.160/Hobson-2016-Futures.pdf LB - Circular economy.

Hollander, M. C., Bakker, C. A. and Hultink, E. J. (2017) 'Product design in a circular economy: Development of a typology of key concepts and terms', Journal of Industrial Ecology, 21(3), pp. 517525. Available at: internal-pdf://189.27.88.138/Hollander_et_al-2017-Journal_of_Industrial_Eco.pdf LB - Circular economy.

Holstov, A., Bridgens, B. N. and Farmer, G. (2015) 'Hygromorphic materials for sustainable responsive architecture', Construction and Building Materials, 98, pp. 570-582. doi: 10.1016/j.conbuildmat.2015.08.136.

Kara, S. et al. (2008) 'Assessment of Products for Optimal Lifetime', CIRP Annals - Manufacturing Technology, 57(1), pp. 1-4. Available at: internal-pdf://92.72.42.150/Kara-2008-CIRP Annals Manufacturing Technolo.pdf LB - longevity and optimal lifetimes.

Karana, E. et al. (2015) 'Material driven design (MDD): A method to design for material experiences', International Journal of Design, 9(2), pp. 35-54. Available at: internal-pdf://0304089172/Karana-2015International journal of design, 1.pdf LB - material selection.

Karana, E., Hekkert, P. and Kandachar, P. (2010) 'A Tool for Meaning Driven Materials Selection', Materials \& Design, 31(6), pp. 2932-2941. Available at: internal-pdf://0412776091/Karana-2010Materials \& Design.pdf.

Karana, E. and Hekkert, P. P. M. (2008) 'Attributing Meanings to Materials', 6th Conference on Design and Emotion: Dare to Desire. Edited by P. M. A. Desmet et al. Hong Kong, Hong Kong SAR: TU Delft, pp. 1-18. Available at: internal-pdf://0628175008/Karana-2008-6th Conference on Design and Emoti.pdf.

Karana, E., Pedgley, O. and Rognoli, V. (2013) Materials Experience: fundamentals of materials and design. Butterworth-Heinemann. Available at: internal-pdf://0719885359/Karana-2013.pdf LB material selection.

van Kesteren, I. E. H. (2008) 'Product Designers' Information Needs in Materials Selection', Materials \& Design, 29(1), pp. 133-145. Available at: internal-pdf://116.18.38.185/van Kesteren-2008-Materials 
\& Design.pdf LB - material selection.

Korhonen, J. et al. (2018) 'Circular economy as an essentially contested concept', Journal of Cleaner Production, 175, pp. 544-552. doi: https://doi.org/10.1016/j.jclepro.2017.12.111.

Lee, J. et al. (2015) 'What is "value"and how can we capture it from the product value chain?' Available at: internal-pdf://228.60.152.49/Lee-2015.pdf LB - Circular economy.

Lilley, D. et al. (2016) 'Cosmetic obsolescence? User perceptions of new and artificially aged materials', Materials \& Design. Elsevier Ltd, 101, pp. 355-365. doi: 10.1016/j.matdes.2016.04.012.

Lofthouse, V. A. and Prendeville, S. (2018) 'Human-centred design of products and services for the circular economy-A Review'.

Maffei, N. P. and Fisher, T. (2013) 'Historicizing shininess in design: finding meaning in an unstable phenomenon', Journal of Design History, 26(3), pp. 231-240. doi: 10.1093/jdh/ept025.

Manley, A. H. G. et al. (2016) 'Worn out or worn in? How cosmetic wear affects semantic appraisals of materials', NordiCHI'16 the 9th Nordic Conference on Human-Computer Interaction. Gothenburg, Sweden.

Manley, A. H. G. (2018) Attitudinal Perception of Cosmetic Wear and Damage of Materials within the Use Phase of Portable Electronic Products, School of Design. Loughborough University.

Manley, A. H. G., Lilley, D. and Hurn, K. (2015a) 'Cosmetic Wear and Affective Responses in Digital Products: Towards an understanding of what types of cosmetic wear cause what types of attitudinal responses from smartphone users.', in PLATE. Nottingham Trent University. Available at: internalpdf://117.69.225.65/Manley-2015-PLATE.pdf LB - material ageing.

Manley, A. H. G., Lilley, D. and Hurn, K. (2015b) 'Wear and affect: cosmetic obsolescence of plastics in digital products', in Proceedings of 2015 Provocative Plastics international conference.

Bournemouth: Arts University Bournemouth. Available at: internal-pdf://0719885347/Manley-2015.pdf LB - material ageing.

McDonough, W. and Braungart, M. (2002) Cradle to cradle: remaking the way we make things. First edit. North Point Press. Available at: internal-pdf://189.27.88.154/McDonough-2002.pdf LB - Circular economy.

Mugge, R., Schoormans, J. P. L. and Schifferstein, H. N. J. (2005) 'Design strategies to postpone consumers' product replacement: The value of a strong person-product relationship', The Design Journal, 8(2), pp. 38-48. Available at: internal-pdf://141.237.114.99/Mugge-2005-The Design Journal.pdf LB - emotionally durable design.

Van Nes, N. and Cramer, J. (2006) 'Product lifetime optimization: a challenging strategy towards more sustainable consumption patterns', Journal of Cleaner Production, 14(15), pp. 1307-1318. Available at: internal-pdf://0749241872/Van Nes-2006-Journal of Cleaner Production.pdf LB - longevity and optimal lifetimes.

Nobels, E. et al. (2015) 'Materials, Time and Emotion: how materials change in time?', in EKSIG 2015-TANGIBLE MEANS experiential knowledge through materials. Available at: internalpdf://228.60.152.58/Nobels-2015-EKSIG 2015-TANGIBLE MEANS experien.pdf LB - material ageing.

Odom, W. and Pierce, J. (2009) 'Improving with age: designing enduring interactive products', in CHI'09 Extended Abstracts on Human Factors in Computing Systems. Boston, USA: ACM, pp. 37933798. Available at: internal-pdf://0304089166/Odom-2009-CHI'09 Extended Abstracts on Human F.pdf LB - emotionally durable design longevity and optimal lifetimes.

Oliver, K., Seddon, A. and Trask, R. S. (2016) 'Morphing in nature and beyond: a review of natural and synthetic shape-changing materials and mechanisms', Journal of Materials Science, pp. 1-27. doi: 10.1007/s10853-016-0295-8.

Osgood, C. E. (1964) 'Semantic differential technique in the comparative study of cultures', American Anthropologist, 66(3), pp. 171-200.

Packard, V. (1963) The waste makers. Penguin Books Harmondsworth.

Park, M. B. (2009) Product life: designing for longer lifespans. Kingston University London. Available at: internal-pdf://0719885334/Park-2009.pdf LB - longevity and optimal lifetimes. 
Pedgley, O. et al. (2018) 'Embracing Material Surface Imperfections in Product Design', International Journal of Design, 12(3), pp. 21-33.

Pedgley, O., Rognoli, V. and Karana, E. (2016) 'Materials experience as a foundation for materials and design education', International Journal of Technology and Design Education, 26(4), pp. 613630.

Prieto-Sandoval, V., Jaca, C. and Ormazabal, M. (2017) 'Towards a consensus on the circular economy', Journal of Cleaner Production. doi: https://doi.org/10.1016/j.jclepro.2017.12.224.

Pye, D. (1968) The Nature and Art of Workmanship. London: A\&C Black Publishers. Available at: http://books.google.co.uk/books?id=APmfGAAACAAJ.

Rogers, J. et al. (2015) 'Product Longevity and Shared Ownership: Sustainable Routes to Satisfying the World'S Growing Demand for Goods', AIMS Energy, 3(4), pp. 547-561. Available at: internalpdf://141.237.114.96/Rogers-2015-AIMS Energy.pdf LB - longevity and optimal lifetimes.

Rognoli, V. et al. (2015) 'DIY materials', Materials \& Design, 86, pp. 692-702.

Rognoli, V. and Karana, E. (2014) 'Towards a new materials aesthetic based on imperfection and graceful ageing', in Materials experience: Fundamentals of materials and design, pp. 145-154. Available at: internal-pdf://189.27.88.180/Rognoli-2014-Materials experience_Fundamental.pdf LB imperfection.

Salvia, G. et al. (2015) 'What is broken? Expected lifetime, perception of brokenness and attitude towards maintenance and repair', Product Lifetimes And The Environment. Nottingham Trent University. Available at: internal-pdf://0719885360/Salvia-2015-PLATE_Product Lifetimes And The E.pdf LB - longevity and optimal lifetimes.

Skedung, L. et al. (2011) 'Tactile perception: Finger friction, surface roughness and perceived coarseness', Tribology International, 44, pp. 505-512. Available at: internal-

pdf://108.234.240.134/Skedung-2011-Tribology International.pdf LB - material perception.

Soroudi, A. and Jakubowicz, I. (2013) 'Recycling of bioplastics, their blends and biocomposites: A review', European Polymer Journal, 49(10), pp. 2839-2858.

Spence, C. et al. (2016) "When Sandpaper Is "Kiki" and Satin Is "Bouba": an Exploration of the Associations Between Words, Emotional States, and the Tactile Attributes of Everyday Materials', Multisensory Research, 29(1-3), pp. 133-155. doi: 10.1163/22134808-00002497.

Studart, A. R. and Erb, R. M. (2014) 'Bioinspired materials that self-shape through programmed microstructures', Soft matter, 10(9), pp. 1284-1294.

Suckling, J. and Lee, J. (2015) 'Redefining scope: the true environmental impact of smartphones?', The International Journal of Life Cycle Assessment, 20(8), pp. 1181-1196. doi: 10.1007/s11367-0150909-4.

Thompson, R. (2017) The Materials Sourcebook for Design Professionals. Thames \& Hudson.

Virtanen, M., Manskinen, K. and Eerola, S. (2017) 'Circular Material Library. An Innovative Tool to Design Circular Economy', The Design Journal, 20(sup1), pp. S1611-S1619. Available at: internalpdf://80.126.215.165/Circular Material Library An Innovative Tool t.pdf LB - material libraries.

Wastiels, L. et al. (2012) 'Red or rough, what makes materials warmer?', Materials and Design. doi: 10.1016/j.matdes.2012.06.028.

Wastling, T., Charnley, F. and Moreno, M. (2018) 'Design for Circular Behaviour: Considering Users in a Circular Economy', Sustainability, 10(6), p. 1743.

Wilkes, S. et al. (2016) 'Design tools for interdisciplinary translation of material experiences', Materials \& Design, 90. doi: http://dx.doi.org/.

Wilkes, S. E. and Miodownik, M. A. (2018) 'Materials library collections as tools for interdisciplinary research', Interdisciplinary Science Reviews, 43(1), pp. 3-23. Available at: internalpdf://0719885330/Materials library collections as tools for int.pdf LB - material libraries.

Wilson, G. T. et al. (2015) 'Single product, multi-lifetime components: challenges for Product-Service System development', PLATE: Product Lifetimes and The Environment. Nottingham Trent University.

Wongsriruksa, S. et al. (2012) 'The Use of Physical Property Data to Predict the Touch Perception of 
Materials', Materials \& Design, 42, pp. 238-244. Available at: internal-

pdf://194.194.150.188/Wongsriruksa-2012-Materials \& Design.pdf LB - material perception.

Woolley, M. (2003) 'Choreographing obsolescence-ecodesign: the pleasure/dissatisfaction cycle', in Proceedings of the 2003 international conference on Designing pleasurable products and interfaces. ACM, pp. 77-81. Available at: internal-pdf://228.60.152.36/Woolley-2003-Proceedings of the 2003 internati.pdf LB - material ageing.

Zijlema, A. F., van den Hoven, E. and Eggen, J. H. (2017) 'Preserving objects, preserving memories: Repair professionals and object owners on the relation between traces on personal possessions and memories', Delft University of Technology, 8, p. 10. 